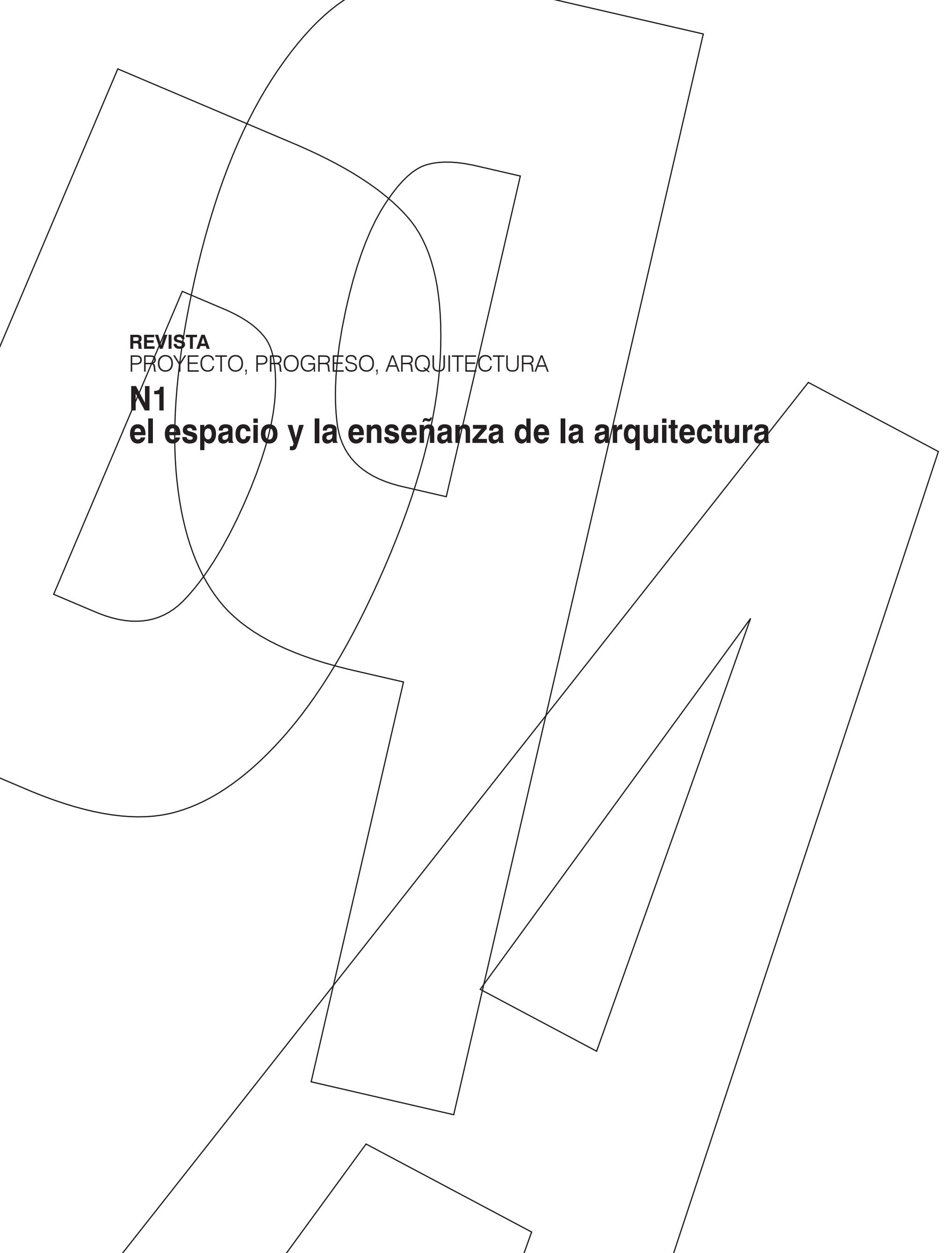





RESUMEN Este artículo analiza el edificio de la Facultad de Arquitectura y Urbanismo para la U.S.P. construido por Vilanova Artigas en 1961. Se inicia el estudio estableciendo una relación con las obras precedentes, con las casas que construyó a finales de los años cuarenta, donde Artigas asienta las bases de una arquitectura caracterizada por el uso del hormigón armado iniciando una particular forma de relacionar sus obras con el lugar y su contexto. Se pone de manifiesto la importancia de un pensamiento y de unas convicciones ideológicas que Artigas hará presentes en su arquitectura con especial énfasis en este edificio. Generado desde la idea de gran contenedor, se establecen relaciones con otras obras importantes de la época que sitúan a la F.A.U. en el contexto internacional valorando adecuadamente la aportación de Artigas al desarrollo moderno. Se estudian las características más significativas del edificio: la utilización de la estructura en la definición espacial, la manipulación de la cota cero o el uso del programa para comprobar las ideas del proyecto. Con estos instrumentos, se coloniza el gran interior cubierto, recurriendo a relaciones definidas y conocidas de otros espacios habitables para responder adecuadamente a la escala humana. La plaza interior, "la sala caramelo", fue el escenario sobre el que basculó toda esta operación; un espacio no exento de intencionalidad política en un momento de ausencia de libertades. El modelo de enseñanza, resultado de una idea de arquitectura y del compromiso social y político de Artigas, es la comprobación última que cierra este discurso y da validez a este edificio.

PALABRAS CLAVE FAU-USP, Artigas, Arquitectura, Enseñanza, Espacio docente, Lugar

SUMMARY The article analyses the Architecture and Urbanism Faculty building for the University of Säo Paulo, constructed by Vilanova Artigas in 1961. The study begins by establishing a relationship with his preceding works, with the houses that he constructed at the end of the Forties. This is where Artigas establishes the basics of an architecture characterised by the use of reinforced concrete and where he begins a particular way of relating his works to the place and its context. The importance of the thought and ideological convictions, which Artigas introduced into his architecture, will be made clear with special emphasis on the analysed building. Generated from the idea of a large container, relationships with other important works of the time are established which place the A.U. F. in the international context and properly evaluate the contribution of Artigas to modern development. The most significant characteristics of the building are studied: the use of the structure in the spatial definition, the transformation of level zero or use of the programme to verify the ideas of the project. The colonization of the large covered interior, turning to clear and known relationships to other inhabitable spaces, to respond appropriately to the human scale. The interior plaza, the "Caramel Hall", was the scene on which the whole operation balanced, a space not without political intent at a time of limited freedom. The educational model, the result of an architectural idea and the social and political commitment of Artigas, is the ultimate test which gives validity to this building and closes this article

KEYWORDS AUF-USP, Artigas, Architecture, Education, Educational Space, Place. 


\title{
LA FAU-USP DE VILANOVA ARTIGAS (1961): ARQUITECTURA Y MODELO DE ENSEÑANZA
}

AUF-USP BY VILANOVA ARTIGAS (1961): ARCHITECTURE AND EDUCATIONAL MODEL

Amadeo Ramos Carranza

\begin{abstract}
"Raramente el ingeniero ve Arquitectura más allá del diseño de un edificio. Rodear la arquitectura con el significado cultural y artístico que tiene, no es tarea fácil. Es muy difícil hasta para los propios arquitectos que, de vez en cuando, degeneran en constructores. Tener el coraje de asimilar la condición del arquitecto como un artista no es una vanidad, sino la necesidad de formar una conciencia, una visión del mundo"
\end{abstract}

ARTIGAS, Vilanova. Vilanova Artigas. Lisboa: Editorial Blau, Lda., 1997, p.26

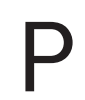

royectar una escuela de arquitectura es para un arquitecto una oportunidad para defender la arquitectura en la que cree y para proponer los espacios más adecuados para su enseñanza y su aprendizaje. Algunos arquitectos del siglo XX que tuvieron esta posibilidad, supieron conjugar las circunstancias históricas de su momento con el pensamiento que sustentaba su arquitectura. En este sentido, la Facultad de Arquitectura y Urbanismo que construyó Vilanova Artigas en Sao Paulo en el año 1961, es un ejemplo; la intensa actividad y compromiso que demostró Artigas a lo largo de sus años están en gran medida presentes en ella. Sería un error observarla como un hecho aislado sin considerar ni reconocer que una idea de arquitectura se construye, normalmente, a lo largo de varios años. Además, a pesar del interés de su trabajo, ni su pensamiento ni su arquitectura se encuentran suficientemente difundidos.

\section{IDEOLOGÍA Y FUNDAMENTOS EN LA ARQUITECTURA DE ARTIGAS}

De Artigas están estudiados sus años de formación y sus compromisos políticos-culturales gracias a sus escritos en los que nos narró aspectos esenciales de su vida. Sus textos sobre la arquitectura y su enseñanza, adquieren la importancia del legado teórico que completaba una actividad intelectual a la que parecían obligados aquellos arquitectos que tuvieron que desarrollar su arquitectura inmediatamente después de los años más significativos del Movimiento Moderno.

Su obra quedó definida por el constante empleo del hormigón armado como material de construcción y como técnica con la que producir su arquitectura. Una práctica que condicionó y reforzó su pensamiento y facilitó incorporar el compromiso social que, a su juicio, la arquitectura debía asumir. Otra característica de su obra fue la manera de acomodar sus edificios en el territorio: una particular forma de adaptar y transformar el suelo ocupado.

En la elección del hormigón armado pudieron influir las asignaturas que cursó en la Escuela de Ingeniería de Paraná antes de pasar a la Escuela Politécnica de Sao Paulo donde completó su formación como arquitecto² ${ }^{2}$ Artigas se interesó por el conocimiento específico sobre los materiales que fueron expresión de la industria moderna, aquellos que, como el hormigón armado, posibilitaron en arquitectura nuevos ensayos, anticiparon la producción a gran escala, ayudaron a introducir conceptos como seriación, racionalización, estandarización o prefabricación y permitieron pensar que otra sociedad era posible. Desarrollando su arquitectura desde los principios asociados a las escuelas de ingeniería y politécnicas pudo descubrir también la importancia de la eficiencia mecánica en la construcción, de eliminar lo superfluo como criterio básico de economía, de diseñar piezas destinadas a cumplir una función específica, o de pensar la mejor manera en la que han de trabajar los materiales empleados. La formación técnica es un conocimiento que ayuda al arquitecto en su labor: le permite observar las reglas del cálculo y trasladar convenientemente su aplicación a la construcción de la arquitectura. No se trata de elegir entre los materiales de la industria moderna -hormigón, acero, vidrio, aluminio, etc.- y los que mejor pueden representar a la naturaleza -piedra, ladrillo, barro, etc.-; en la arquitectura de Artigas, construir significaba servirse de los avances técnicos y de la producción industrial para crear mejores condiciones de vida.

1. ARTIGAS, Vilanova: Caminhos da arquitetura. Sao Paulo: Lech - Livraria Editora Ciencias Humanas Ltda, 1981. La publicación reúne textos docentes y críticos sobre arquitectura que Artigas escribió entre las décadas 50 y 70.

2. Además de su formación técnica, fue fundamental su experiencia como aprendiz en el estudio Bratke \& Botti (entre 1935 y 1937) donde pudo conocer las técnicas de construcción y el análisis de programas. 


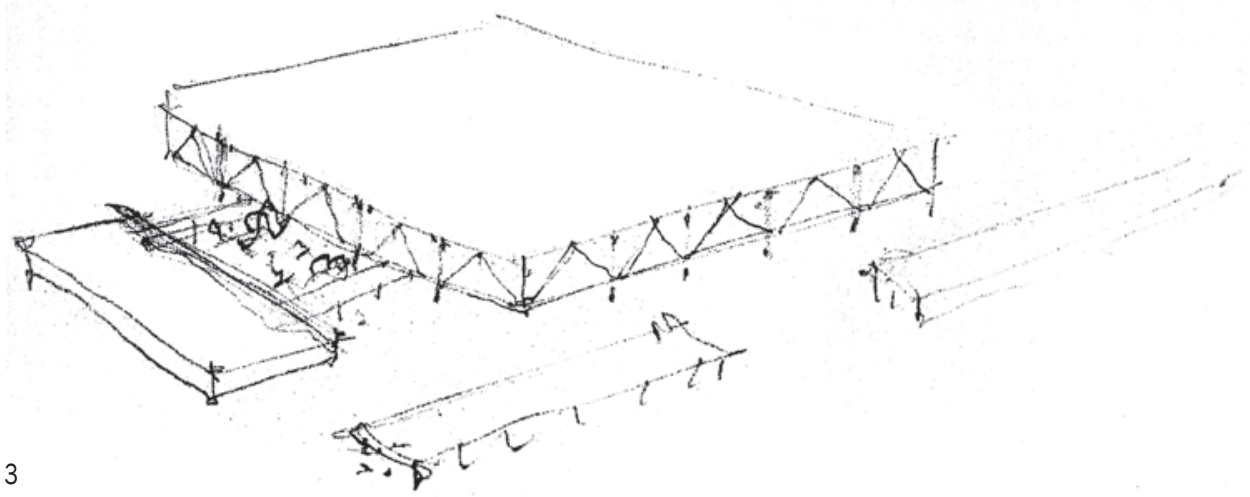

2. Boceto preliminar para el edificio de la FAU. Vilanova Artigas

3. Boceto para el Convention Hall de Chicago. Mies van der Rohe

La arquitectura como instrumento de cambio social y político exigirá a Artigas revisar el legado moderno. La crítica que realizó en los años cuarenta sobre las casas modernas de Warchavchik y de otros arquitectos de la época que, a su juicio, escondían la estructura de la cubierta tras el pretil, iba más allá de una cuestión formal o de la denuncia de una falta de coherencia constructiva. En esta crítica Artigas fundamentará la búsqueda de una estructura única construida con hormigón armado que acotase el ámbito de sus edificios de un solo gesto. La idea de una envolvente diferente pero continua, que dibujase en el paisaje formas revolucionarias, debía tener consecuencias similares a la de los manifiestos vanguardistas destinados a censurar las condiciones acomodadas o deficientes de la arquitectura de su tiempo. Sus casas de finales de los años cuarenta comenzaron a asumir este reto, con una intensidad y un compromiso comparable al que se plantearon otras arquitecturas pasadas. Supuso el intento de transformar un entorno no ordenado, que no era propicio para esta nueva arquitectura, ni era afín a las intenciones buscadas en estos proyectos. Como afirma Joao Kamita, las casas de Artigas "emergen como excepciones extraordinarias en un medio informe". ${ }^{\text {. Con }}$ arquitecturas como la residencia para D'Estefani, la casa Czapski, su segunda casa-estudio (figura 1), la casa Heitor de Almeida o la construida para Taques Bittencourt ${ }^{4}$, conseguirá colonizar el paisaje desde la racionalidad formal y constructiva, distinguiendo a estas obras en los perfiles rurales y urbanos en los que se insertaron. Con la modificación de la topografía conseguirá situarlas en estos entornos; una operación relacionada además con una nueva forma de diseñar y usar los espacios interiores y la aparición de unas estancias abiertas al exterior, pero cobijadas, que funcionaban como patio de la casa. Artigas tomaba prestados invariantes de la arquitectura de Le Corbusier, de gran actualidad en la arquitectura brasileña: necesitaba de los "pilotis" para elevar el volumen y provocar la necesaria reducción del programa en la planta baja, que quedaba liberada estructural y funcionalmente para crear esos umbrales que daban paso a la entrada de la casa. Se consolidaba el uso de la rampa como elemento estructurante del espacio interior que con frecuencia se relacionaba con un espacio abierto, patio o jardín, haciéndose notar también en la forma y en el volumen exterior.

En la imagen prima la envolvente continua y se despierta el interés por el sistema constructivo. El arquitecto brasileño trataba de averiguar cómo construir una arquitectura que funcionase como una "cápsula" que le permitiese crear un mundo nuevo donde poder ensayar otras formas de habitar la arquitectura. Consecuentemente, los espacios más abiertos serán aquellos que estén en contacto directo con el suelo y el perfil rectificado del terreno, al que Artigas dará continuidad hasta incorporarlo a la planta baja de la casa. Ajustándose a la reducida superficie de la parcela, consiguió que sus obras quedasen ancladas a un lugar y reflejasen así su existencia en el territorio y su pertenencia a una geografía caracterizada por la extensión y una fuerte presencia de la naturaleza.

En la arquitectura de Artigas, todo tenderá a acontecer en el interior, allí donde el Movimiento Moderno situó al arquitecto y desde donde trató de buscar formas propias para mejorar una realidad que no siempre le resultaba agradable ${ }^{5}$. Los proyectos de la década de los cincuenta, hasta la construcción la Facultad de Arquitectura y Urbanismo para la Universidad de Sao Paulo (F.A.U.U.S.P.), confirman esta hipótesis: Artigas seguía aquella práctica llevada a cabo por los grandes arquitectos de principios del siglo XX, que consideraron la casa, la villa o la vivienda, el campo de experimentación fundamental a partir del cual construir la ciudad: "...el puente, la estación, el aeropuerto, no son habitaciones, sino complementos, objetos complementarios a la habitación a través de los cuales el espacio de la habitación se universaliza. La ciudad es una casa. La casa es una ciudad..." ${ }^{\prime}$. Bajo la extensa línea horizontal que sobre el paisaje dibujará la cubierta, el arquitecto brasileño dará cobijo a numerosos tipos de escenas urbanas en busca del control espacial del edificio. El volumen, mientras más próximo a la cubierta más hermético se volverá, alterado, a veces, por puntuales actuaciones que interrumpirán el continuo estructural que conforma la cubierta. 


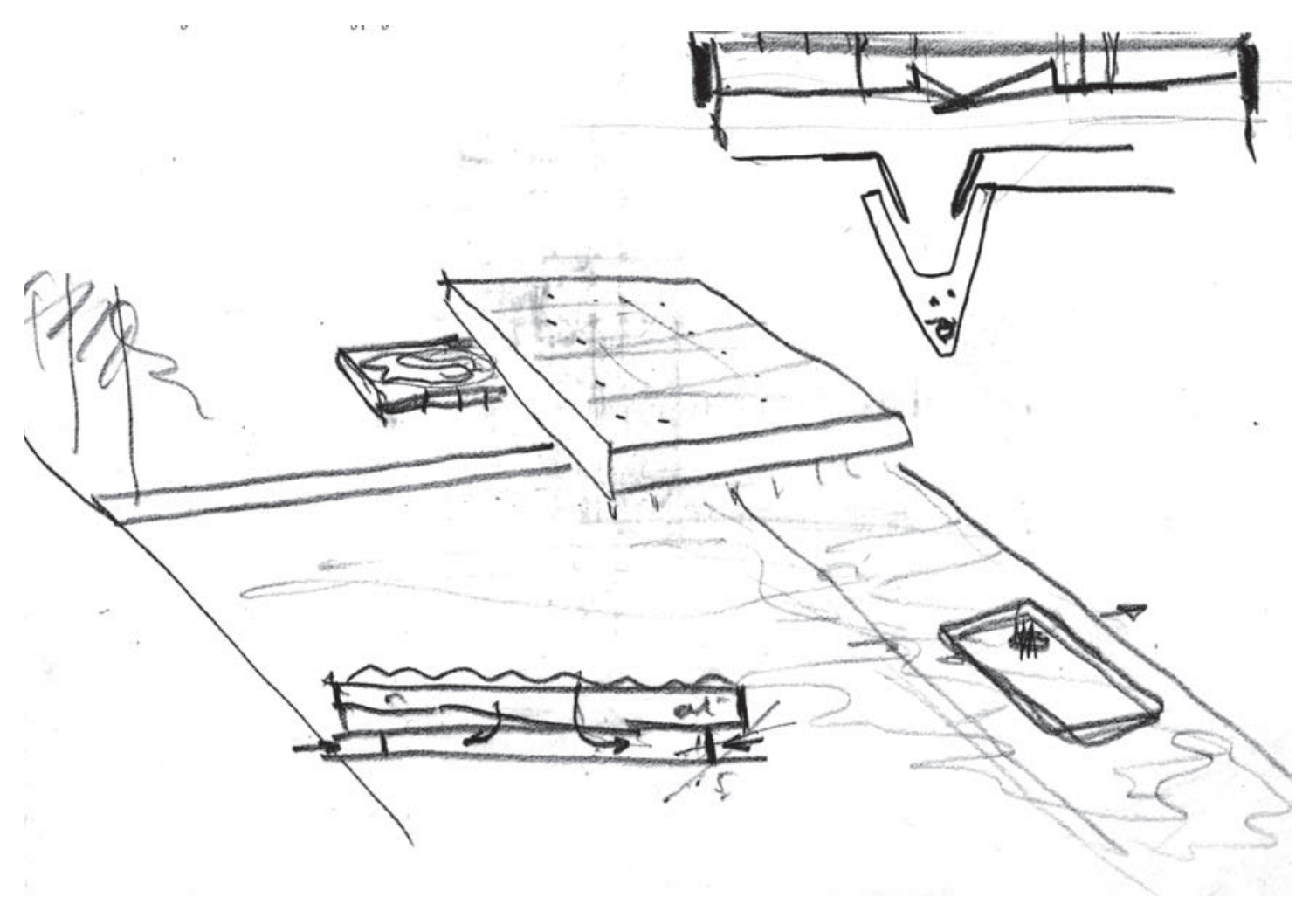

ARQUITECTURA EN LA FACULTAD DE ARQUITECTURA Y URBANISMO (F.A.U.)

\section{Imagen y entorno}

Uno de los bocetos para la F.A.U., nos presenta un volumen autónomo en un paisaje poco caracterizado, del que poco puede deducirse salvo el dominio de la horizontal (figura 2). El edificio otorga identidad al lugar, al dibujarse un territorio ordenado, cartesiano, según las directrices del paralelepípedo proyectado. Un camino, una explanada y un pequeño volumen anexionado al principal, fijan una posición, precisando un lugar y evitando pensar en un hipotético desplazamiento por los alrededores. Las palmeras informan de la posición de la vía principal de acceso y unos trazos irregulares y poco definidos extendidos sobre el suelo, anuncian la posterior colonización que la vegetación hará del lugar una vez terminada la construcción del edificio. La gran superficie que Artigas quería ocupar le obligó a pensar desde el principio en unas condiciones particulares de la planta baja, cuyos espacios deberían facilitar de manera natural la renovación del aire, intuyendo en el croquis la necesidad de un gran vacío en el centro del edificio a modo de "plenum" sobre el que basculase toda la operación del acondicionamiento natural del interior. La cubierta, una línea ondulante que descansa sobre el rectángulo que ocuparían las plantas superiores, parece vincularse a esta solución asumiendo además la misión de iluminar cenitalmente el edificio; las vigas en forma de "V" minimizarían la presencia de la estructura en el interior, ofrecerían una mayor superficie de apoyo para soportar los mecanismos de cubrición e iluminación y ayudarían a la difusión de la luz aprovechando los planos inclinados de las caras laterales de las vigas. Artigas pensaba el proyecto de una manera completa e integrada, sensible al posicionar el edificio en el entorno y anticipándose a los problemas constructivos y funcionales que deberá resolver.

El boceto de Artigas trae a colación otro dibujo: el que realizó Mies van der Rohe para el proyecto del Convention Hall de Chicago (1953-54) (figura 3) y cuya comparación, sirve para aclarar aún más la arquitectura que perseguía Artigas. Con unos volúmenes anejos de menor tamaño, Mies no incorporó a su dibujo características del lugar, aunque en realidad, se trataba de un distrito heterogéneo

3. KAMITA, Joao Masao: Vilanova Artigas. Sao Paulo: Cosac \& Naify Ediçoes. Espaços da arte brasileira, 2000, p. 21.

4. Estas casas fueron diseñadas por Artigas en el año 1949 y se todas se encuentran en Sao Paulo.

5. Una reflexión sobre la concepción de la arquitectura desde el espacio interior puede seguirse en RAMOS CARRANZA, Amadeo: "Estructuras Activas". En Arquitectos, Madrid: Consejo Superior de los Colegios de Arquitectos de España, 2008, n 185, p. 75.

6. ARTIGAS, Vilanova: "Arquitectura e construçao". En ARTIGAS, Vilanova: Caminhos da arquitetura. Op.cit. p. 102. 


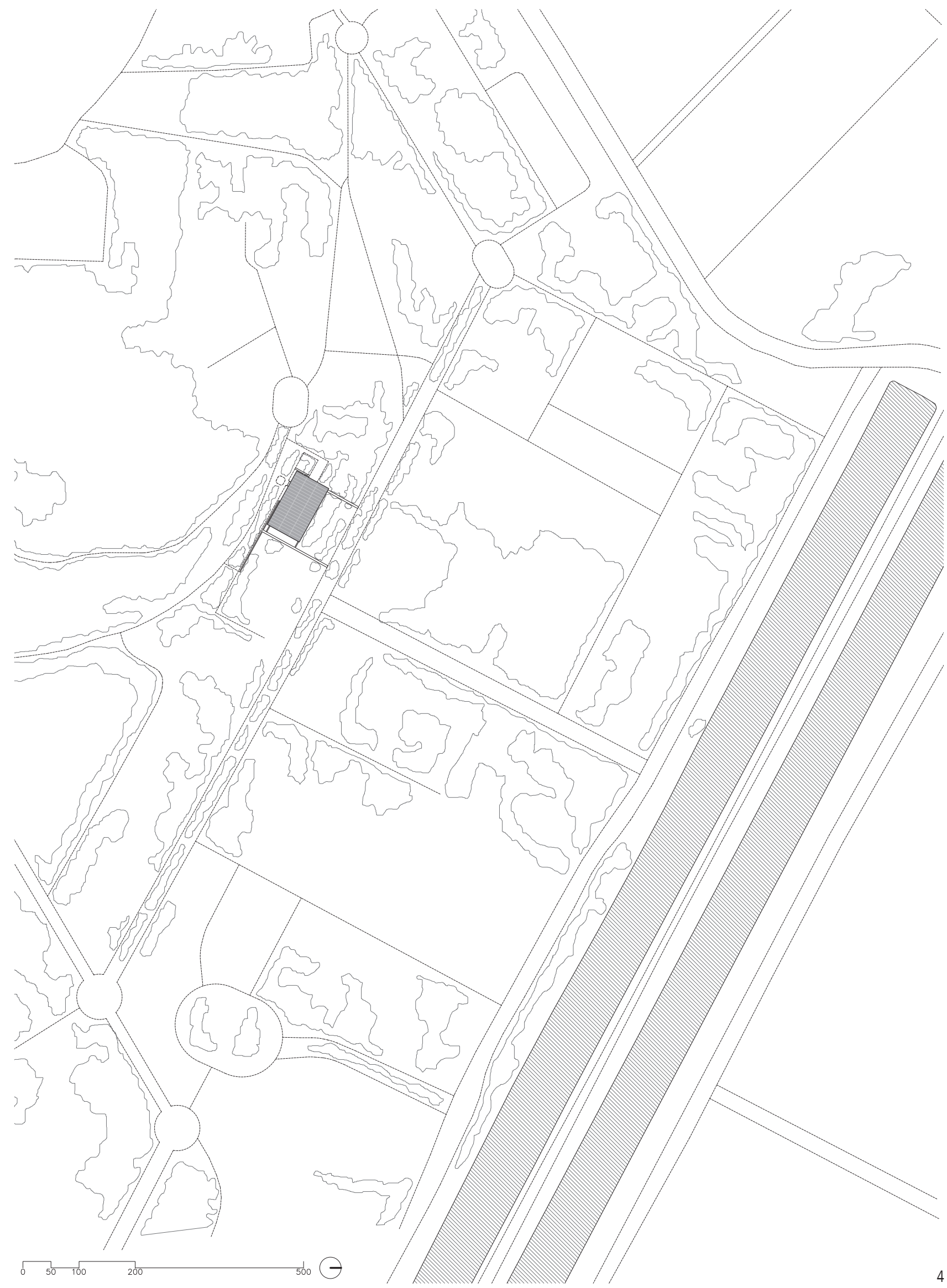


4. Plano de implantación.

Zona Ciudad Universitaria.

Edificio de la F.A.U Estado

actual.

5. Perspectiva entorno. Zona

Ciudad Universitaria. Edificio

de la F.A.U Estado actual.

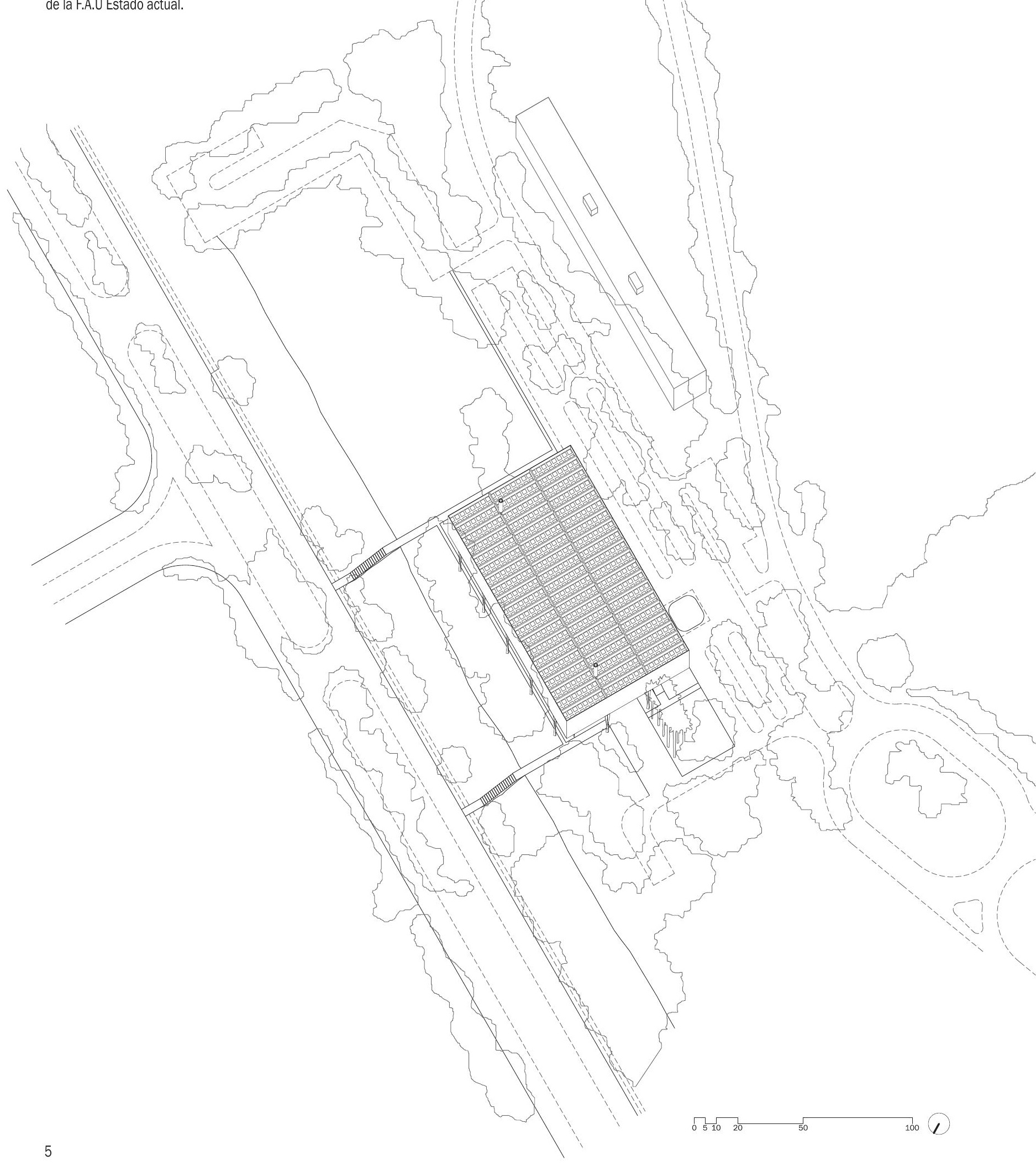


ocupado por edificios comerciales, industriales y viviendas diseminadas y degradadas. Si Mies dibujó en las fachadas una estructura metálica arriostrada, Artigas se limitó a representarlas como un plano ciego, poniendo de manifiesto una diferente concepción de la relación interior-exterior, convencido Artigas de que, en la idea moderna, la transparencia de la forma se volvía problemática. Trataba de evitar que su edificio resultase un volumen indiferenciado y el camino y la explanada tensionaban un dibujo que, observado en conjunto, rompía la simetría del contenedor. El espacio es el fin de todos nuestros esfuerzos y la estructura y la construcción, los medios para alcanzarlo. En este sentido, ambos dibujos son ejemplares al encauzar un proceso de proyecto con el que se superaba la mera función portante encomendada al esqueleto estructural. Posicionar una arquitectura en un entorno sin definir es establecer un criterio de ordenación y orientación, y tanto el camino como la explanada indican en el boceto la situación de la entrada, desplazada del centro edificio, y las direcciones en las que el espacio interior se relacionará con el exterior.

En los planos generales se identifican las principales características del boceto de Artigas: un territorio extenso y una vegetación frondosa (figuras 4 y 5). Se mantiene la disposición del edificio anclado a la avenida principal mediante dos caminos, como las pasarelas de un embarcadero que ha quedado desplazado del margen del río Teité, y en el extremo de una franja de terreno que ha sido ordenado cartesianamente al paso del río por esta zona, ahora canalizadas sus riberas. El volumen menor anexionado desaparece; finalmente reducido a una plataforma sobre el terreno; posicionada ahora en la otra fachada, asumirá la misión de construir el suelo del umbral de la entrada al edificio. Todo el programa se resolverá en el interior del gran contenedor sin otra construcción auxiliar que interfiriese entre edificio y naturaleza. Por esta razón, Artigas elude referir datos relativos a los límites de la parcela o del terreno; la estructura es lo único que necesita para hacer crecer algo en torno a ella ${ }^{7}$.
La idea de ocupar una gran extensión cubierta, ha dado lugar a artificios que se han repetido con frecuencia en la historia de arquitectura moderna, sobre todo a medida que se han ido perfeccionando las técnicas de construcción: desde el Crystal Palace de Joseph Paxton para la Exposición Universal de Londres (1851) -Paxton lo describió como una mesa cubierta por un mantel-, hasta la Staatsbibliothek que Hans Scharoun realizó en Berlín (1964-78). La F.A.U. podría también considerarse como una de esas arquitecturas que supieron crear su propio contexto interior. La gran superficie techada, modulada por las vigas de la cubierta y los pilares que la sustentarían, definen las características formales del contenedor: una planta rectangular doblemente simétrica. Un recinto como este, continuo isótropo y modulado puede dar cabida a múltiples usos y deja de ser algo meramente utilitario o funcional cuando su interior se convierte en la producción de una experiencia intelectual capaz de ser aprehendida. Las primeras experiencias modernas de este tipo nos remiten a las daylight factories americanas de principios del siglo XX, cuyos interiores, apropiados por las mecanizadas cadenas de montaje para la producción en serie, inspiraron una arquitectura con espacios capaces de desarrollar múltiples funciones. Artigas transformará este inicial espacio genérico en un recinto diverso, destinado a una convivencia libre y colectiva; con el programa, conseguirá hacer realidad esta idea y verdaderamente habitable su interior.

\section{Niveles y programa funcional}

En la planta de acceso se concentra parte de la tensión provocada por este tipo de arquitectura. El suelo no se define por un único trazo horizontal, sino por una sucesión de líneas paralelas que refieren distintas alturas en esta planta (figuras 6 y 7). La F.A.U. sigue la línea de trabajo iniciada por Artigas en sus proyectos de los años cuarenta y los cambios de cotas provocarán la fragmentación de la planta de acceso en clara oposición a la contundente e ilimitada visión horizontal de la cubierta. Estos cambios 
de altura repercutirán en la manera de organizar el programa, agrupando en niveles las funciones que debían desarrollarse en el interior. No existirá por tanto, ninguna planta que llegue a ocupar la superficie total que delimita el perímetro del edificio.

El nivel de acceso quedó situado a la cota $+0,80$ metros y se identifica con las funciones administrativas - dirección y portería- y los espacios libres y comunitarios a los que se acceden desde exterior. El grado de ocupación a esta cota es mínimo para facilitar las corrientes de aire que debían garantizar la ventilación en el interior del edificio. La fragmentación en niveles se consigue disponiendo parte del programa semienterrado a la cota - 1,10 metros, los talleres de modelado, tipografía y fotografía (nivel -1), y enterrado a la cota - 3,00 metros, la sala de proyección y el auditorio (nivel -2). La ventilación e iluminación del nivel -2 obligó a una gran apertura en el forjado de la planta de acceso; un patio deprimido orientado al noroeste. La construcción abierta de la fachada noroeste a nivel de suelo, tan solo interrumpida por el primer tramo de la rampa, tiene como objetivo facilitar la entrada de aire y luz a estos espacios situados bajo el nivel de entrada. Desde la cota de acceso se accede también al primer nivel elevado que situado a la cota $+2,70$ metros (nivel 1), se destina a usos más relajados para estudiantes y profesores: bar, museo y locales para asociaciones. La biblioteca, la sala de profesores y la secretaría ocupan el nivel 2, a la cota + 4,60 m. Los dos espacios principales de este nivel, recuperan de nuevo la posición del acceso al edificio del nivel 0 , recreando entre biblioteca y sala de profesores, un espacio vestibular con salida al exterior. Son los últimos espacios de esta parte del edificio con iluminación y ventilación mediante cristaleras, circunstancia que concuerda con la concepción espacial y funcional de estas salas sin divisiones. La zona departamental se ubicó en el nivel 3 (+ 6,50 m); una posición intermedia entre los grandes espacios continuos de uso más frecuente que ocupan los niveles inferiores, y la zona de los talleres, situada en el nivel 4 (cota $+8,40$ m.) y la de las aulas, en el nivel 5 (cota $+10,30 \mathrm{~m}$.). En la zona docente, se llega a la máxima ocupación posible, extendiéndose la superficie hasta las paredes opacas de hormigón que delimitaba la estructura inicial del proyecto de Artigas. La iluminación de estos últimos niveles es cenital.

La organización funcional se refleja en la sección transversal, con el escalonamiento invertido de volúmenes junto a las fachadas y bajo la cubierta. El resultado es consecuente con la imagen del boceto inicial del proyecto, al construir ciegos los cerramientos de los últimos niveles y apostar por la cubierta como único plano de iluminación. Las dos fachadas, la definida por los pilares "cruciformes" del exterior y la que en cada nivel va delimitando los diferentes espacios interiores, confluyen en los cerramientos de hormigón, tratando de cada uno mantener su independencia estructural y funcional. Esta forma de construir se extendió por todo el edificio provocando numerosas situaciones de proximidad entre forjados, pilares, muros, pretiles o barandillas. Se desciende a la escala del detalle, cuyo control es imprescindible en la gran composición de planos y volúmenes superpuestos como el de la zona interdepartamental, que gravita en el interior del edificio. Con la luz cenital, los extensos paramentos de hormigón armado que limitaban los recintos resultaban más livianos; una sensación reforzada por la materialidad propiciada por el sistema constructivo empleado: las texturas resultantes de los encofrados, algunos paramentos pintados en azul y rojo, y los materiales y colores de los pavimentos -color caramelo en la planta de acceso- y de las carpinterías - gris azulado-. 


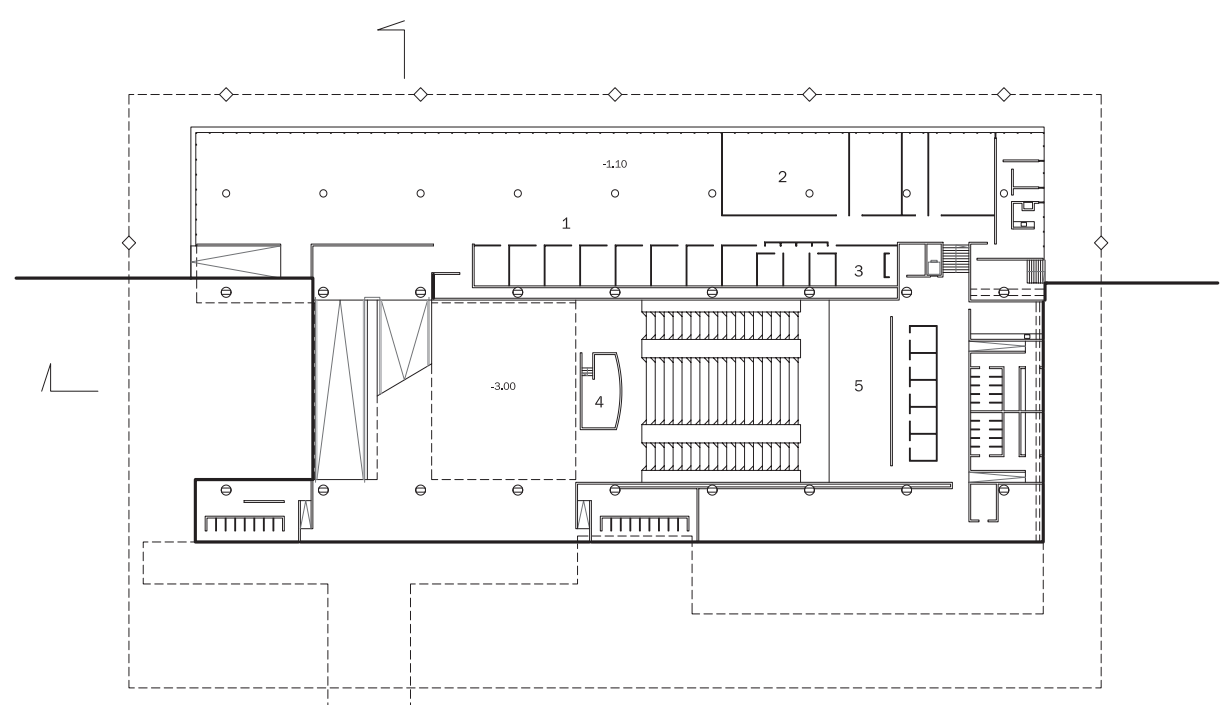

NIVEL -2 $(-3.00 \mathrm{~m}) \quad$ NIVEL $-1 \quad(-1.10 \mathrm{~m})$

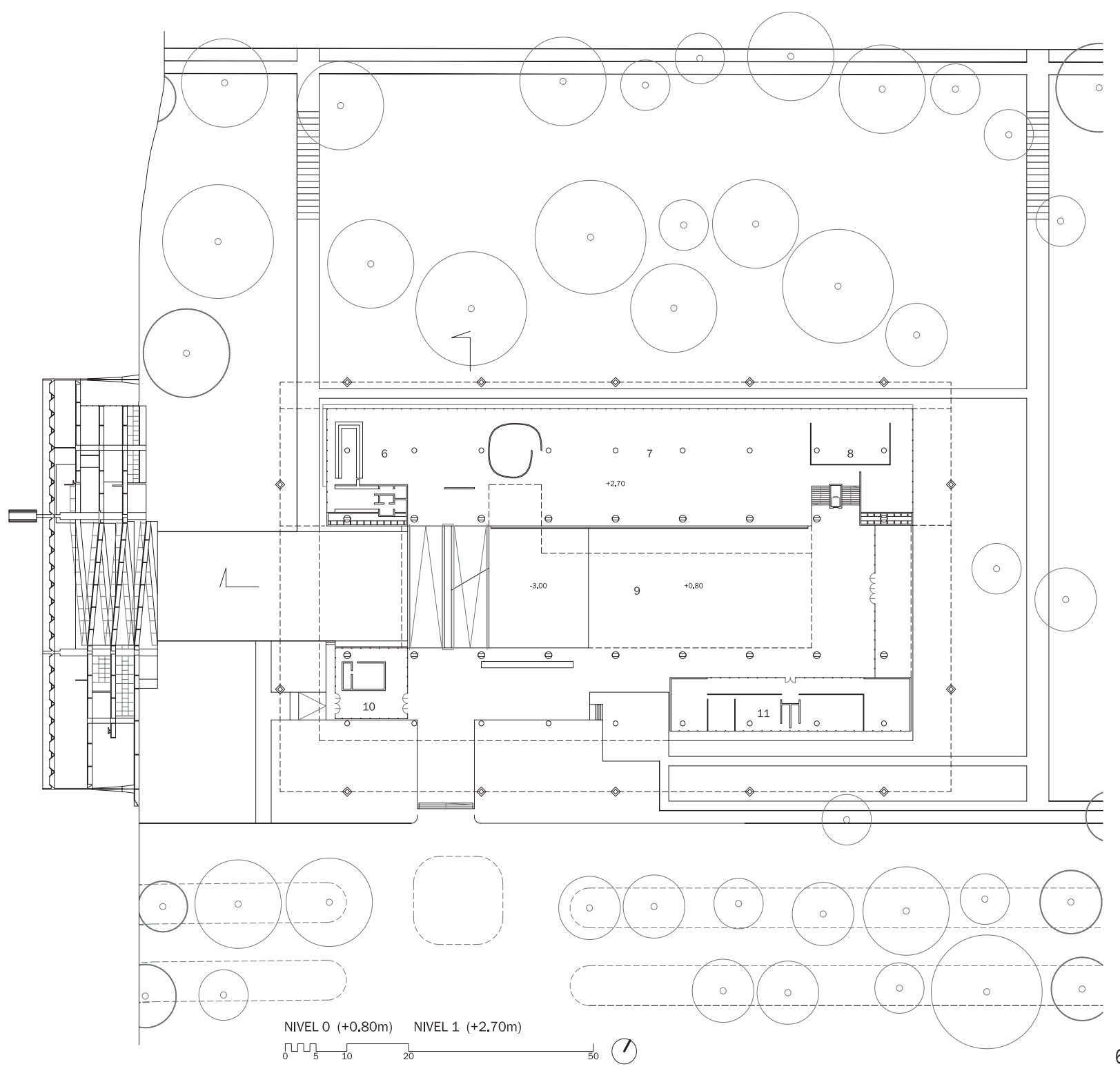


6. Planta nivel $-1(-1,10 \mathrm{~m}$.) y nivel $-2(-3,00 \mathrm{~m}$.$) . Planta$ nivel $0(+0,80 \mathrm{~m}$.) y nivel 1 $(+2,70 \mathrm{~m}$.). Sección transversal por la rampa. Edificio de la F.A.U

7. Planta nivel $2(+4,60 \mathrm{~m}$.) y nivel $3(+6,50 \mathrm{~m}$.). Planta nivel $4(+8,40 \mathrm{~m}$.) y nivel 5 (+10,30 m.). Sección longitudinal. Edificio de la F.A.U.
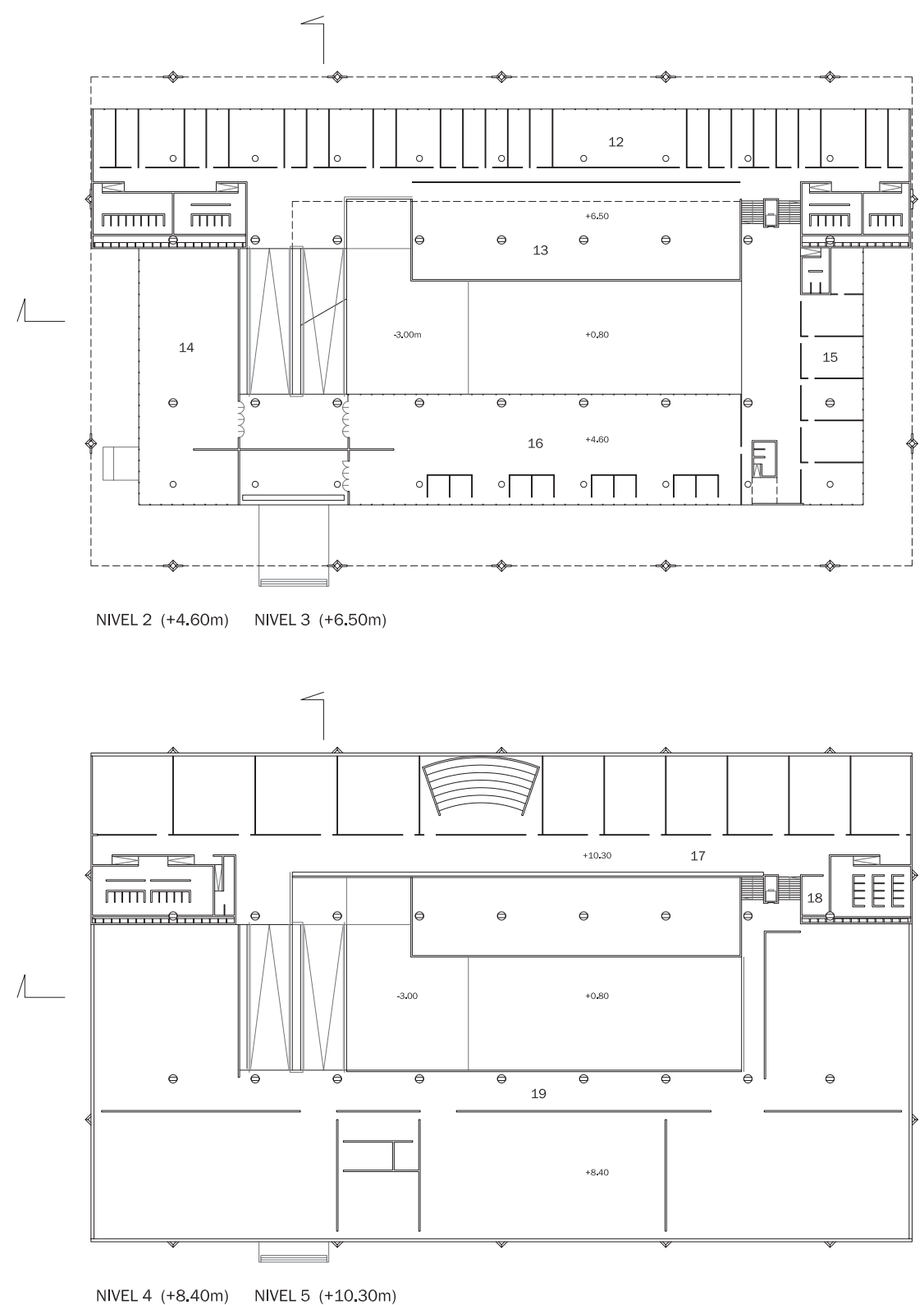

NIVEL $4(+8.40 m) \quad$ NIVEL $5(+10.30 m)$

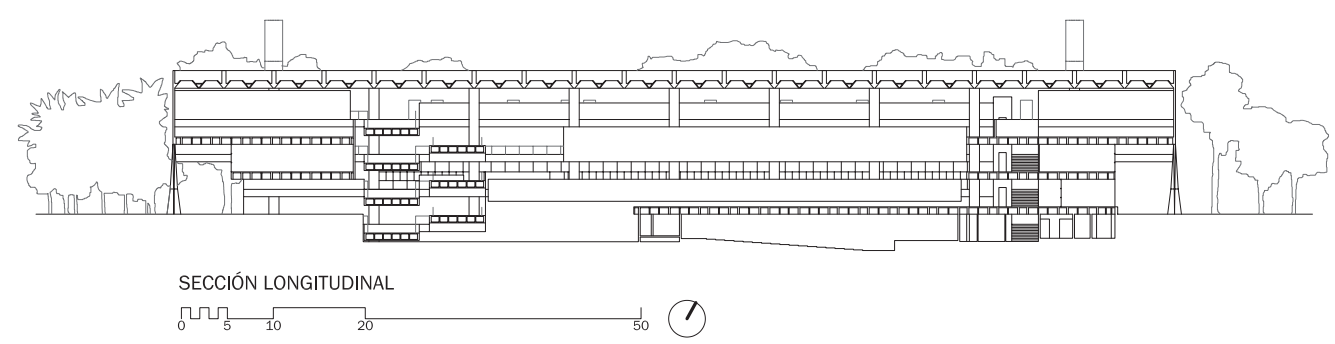



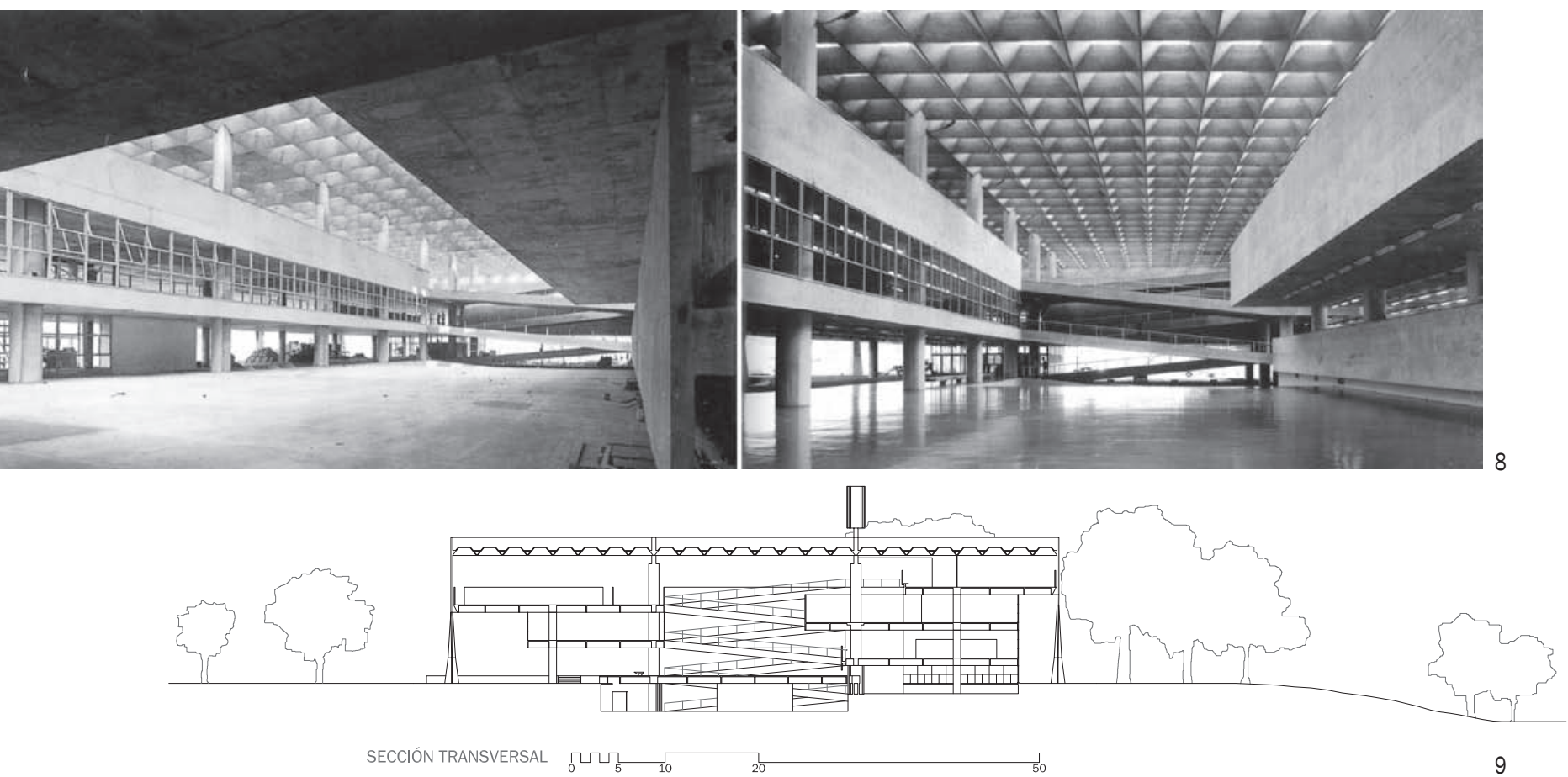

\section{Escenarios urbanos}

La rampa que Artigas había incorporado a su arquitectura a partir de los años cuarenta es el elemento que da credibilidad a la organización del edificio en niveles, facilitando además las conexiones entre ellos. Junto a la rampa, el patio central se convierte en la plaza interior, la "sala caramelo", que será el lugar que justifica todas las relaciones espaciales y funcionales que se producen en el edificio, tanto en el interior como en el exterior (figuras 8 y 9). El amplio recorrido circular en torno a la rampa y junto a la plaza, permite la visión simultánea de todos los niveles convirtiéndose en un observatorio que orienta e informa al visitante de cómo están organizadas las diferentes zonas funcionales. Para ello, fue importante decidir que las divisiones verticales, sobre todo las que delimitaban el espacio de la plaza, no se construyesen opacas hasta el techo, resolviéndose con pretiles, barandillas o cristaleras.

Artigas resolvió la llegada a este interior de una manera excepcional y antecediendo a la entrada, entre los pilares exteriores y las fachadas acristaladas, diseñó un gran espacio porticado definido por la escala de su construcción (figuras 10 y 11). A lo largo de toda la fachada se extiende el gran vuelo del último nivel y los límites de este espacio porticado se ven reforzado por la sombra que arroja este volumen; un espacio a menor temperatura previo al acceso que responde también a las condiciones climáticas de la zona geográfica en la que se encuentra esta arquitectura. Se reconoce la plataforma que identifica el umbral exterior de acceso a la F.A.U., recuerdo de aquel volumen inicial dibujado por Artigas en su boceto y el intento de capturar en el edificio parte de esa naturaleza circundante. Se puede explicar desde esta intención el diseño inspirado en las formas arbóreas de los pilares del contorno exterior construidos en doble cruz: un triángulo invertido de escaso espesor que se intersecciona con una pirámide de base cuadrangular para resolver también la transición entre la delgada pared portante de hormigón que cierra los niveles superiores y la inercia que se necesita en la base del pilar para otorgar rigidez al sistema estructural. La dimensión horizontal dominante del paisaje se refleja en los avances de los forjados y en el retranqueo de los pilares circulares; la iluminación artificial ordenada, queda paralela a la fachada. En el nivel de acceso no hay puertas y en el inmediatamente superior, las cristaleras se alternan con otras zonas abiertas, sin cerramientos. Se muestra al exterior, el espacio vestibular de la cota $+2,70$ metros, frente a la rampa, y entre la biblioteca y la sala de profesores. Se anuncian ámbitos ajustados a otra escala donde la estructura será un instrumento útil para referenciar posiciones -exterior/interior-y para distinguir los límites de los diferentes espacios que completan cada nivel. Auguste Perret ya mostró las nuevas posibilidades espaciales que podían conseguirse introduciendo un doble sistema portante con intenciones y funciones diferenciadas. ${ }^{8}$ Los espacios intermedios creados ayudaron a revisar la relación entre estructura y cerramiento. En el edificio de la Asociación de Hilanderos de Ahmedabad (1954-57), Le Corbusier explotó las posibilidades espaciales que resultaron de emplear un doble orden estructural enfrentando los pilares circulares de los pórticos de la fachada este con la superestructura de los brise-soleil (figura 12). Artigas también enfrentó en el interior escalas diferentes y utilizó la estructura como un sistema de referencia para situar los diversos recintos espaciales que debían albergar el programa9 . En el edificio de Le Corbusier, la pasarela exterior y la escalera 
8. Vistas de la Sala Caramelo y de la rampa desde el nivel 0 (cota $+0,80$ metros).

9. Sección transversal por la Sala Caramelo. Edificio de la F.A.U.

10. Entrada principal al edificio de la F.A.U. Espacio porticado exterior y umbral de entrada.

11. Alzado entrada al edificio de la F.A.U.

12. Talleres interdepartamemtales, F.A.U. (1961), Vilanova Artigas. Edificio de la Asociación de Hilanderos de Ahmedabad (1954-57), Le Corbusier. Espacio interior.

11

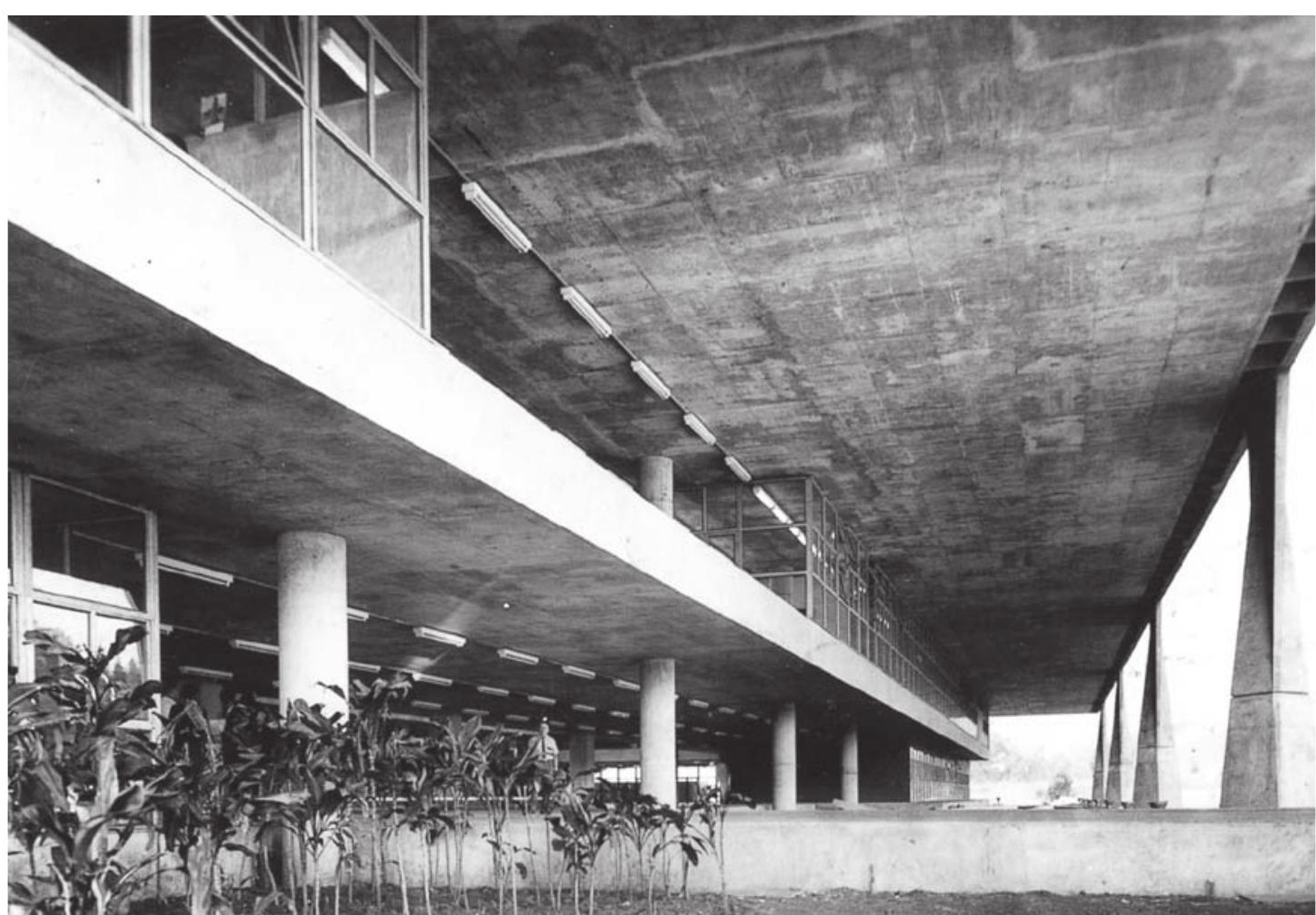

ALZADO PRINCIPAL $\underset{0}{П} \underset{5}{10} \sqrt{20}$
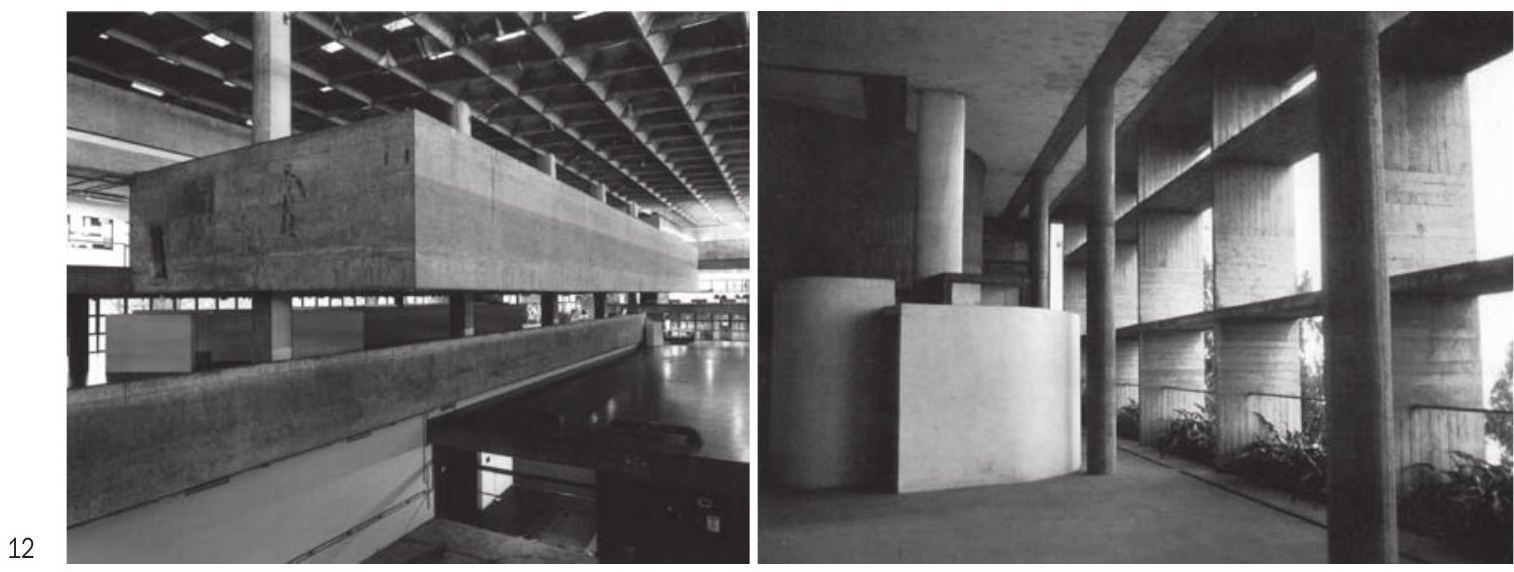

8. La superposición de los dos sistemas estructurales estaba relacionada con la doble escala que presentaban interior y exterior. Perret expresaba así su sentido de la arquitectura, y a su juicio, la mejor manera de conseguirlo era creando una nave que contuviese de un solo golpe todas las necesidades. En el año 1943 resumió este pensamiento en lo que él denominó “el abrigo soberano". GARGIANI, Roberto: Auguste Perret: teoria e opere. Milano: Electa 1993.

9. En la obra de Artigas, la doble escala, exterior-interior que presentan sus edificios parte del empleo de una cubierta continua de gran extensión: el "Ginásio de Guarulhos" (1960), los "Vestiários de Sao Paulo Futebol Club" (1961), el "Anhembi Tênis Club” (1961), el "Garagem de barcos do Santa Paula late Clube" (1961), que anteceden a la FAU, o en obras posteriores como el "Ginásio de Utinga” (1962) o la "Colônia de Férias dos Têxtiles” (1969). 
13. Zona docente: vista de los talleres, pasillo acceso aulas específicas, rampa y Sala Caramelo.

delimitan la entrada interrumpiendo la estructura de los brise-soleil10. En el caso de la F.A.U., tan sólo unos escalones en el camino de acceso y la plataforma situada a la cota + 0,80 metros anuncian este doble espacio previo al edificio así como los diferentes niveles del interior. La imagen cerrada, resulta permeable a las presiones del entorno exterior, provocando una diversidad espacial aparentemente contradictoria a la homogénea construcción y a su estructura doblemente simétrica. La situación de las entradas es decisiva, porque además de la "huella" que deja en las fachadas, sirven para enlazar el exterior con el espacio central de la "sala caramelo". La llegada a la plaza se produce tras observarla desde estos accesos, o en sentido longitudinal o en la dirección de la diagonal (máxima dimensión del espacio), forzada esta visión por la posición de la rampa y el vacío de iluminación de las salas situadas en el nivel -2 . La relación con lo que está fuera del edificio, pone aún más en valor la jerarquía y la organización funcional de los espacios interiores.

Con los movimientos ascendentes o descendentes entre niveles, Artigas aseguraba proporcionar los espacios interiores a la escala del hombre, estableciendo además relaciones definidas y conocidas con otros espacios habitables ampliamente experimentados. Recordando a Louis I. Kahn cuando afirmaba que "la calle es, probablemente, la primera institución del hombre; un lugar de encuentro carente de cubierta, (...) la escuela es un ámbito de espacios donde es bello aprender (...) la ciudad es el lugar de reunión de las instituciones"11, se puede comprender el empeño de Artigas por crear en el interior de sus obras espacios que refieren escenas urbanas porque significa trasladar de la ciudad al edificio, lugares reconocibles tradicionalmente ocupados por las personas. Desde fuera, desde las terrazas y balcones, la plaza es lugar de convergencia y de estancia; desde su interior, es un lugar de partida que nos invita a recorrer las calles próximas y adentrarnos en otros espacios adyacentes. La rampa, fondo de este escenario urbano, es una calle plegada que va salvando una topográfica creada artificialmente, relacionando, ascendiendo o descendiendo, espacio con programa funcional. En los niveles superiores, Artigas recupera la visión completa del edificio; la iluminación cenital uniforme, a lo lejos confundiéndose con la estructura de los casetones, aumenta las dimensiones de estas plantas al tiempo que la continuidad la cubierta indica el fin de la intensa experiencia espacial vivida y provocada por los sucesivos cambios de nivel (figura 13).

La plaza cubierta, la luz cenital, la continuidad espacial entre dependencias, parecen capturar un espacio perteneciente a otro lugar y a otro momento, pero manteniendo la fuerza necesaria para hacer girar sobre sí mismo todo lo que acontece en el interior, protegiendo de esta manera el lugar más íntimo de esta arquitectura. En este sentido, el proyecto de Artigas recuerda algunos ensayos de este tipo realizados por Frank Lloyd Wright ${ }^{12}$, lo que ayuda a comprender mejor la aportación tipológica del arquitecto brasileño. Wright, que organizó edificios a partir un espacio central cubierto con iluminación cenital, relacionaba planta y sección para conseguir una continuidad espacial que partía de las salas perimetrales y llegaba hasta el gran vacío central. En el Larkin Company Administration Building utilizó además esta tipología para ensayar una forma de trabajo novedosa: empleados y ejecutivos trabajarían juntos, sin separaciones físicas, renunciando los dirigentes a los despachos privados: una idea de integración social fomentada desde el modelo arquitectónico. Artigas con una estructura bidireccional trató de conseguir que los interiores se ordenasen independientes de la retícula de pilares, aproximándose más a lo experimentado por Wright en el edificio administrativo de la Johnson.

\section{LA F.A.U. Y EL MODELO DE ENSEÑANZA}

La Facultad de Arquitectura y Urbanismo de la Universidad de Sao Paulo permitió a Artigas revisar la forma de enseñanza y aprendizaje de la Arquitectura, ideando un modelo que respondiese a la formación que el creía idónea para un arquitecto de su tiempo.

Esta idea debía además partir de una adecuada disposición del programa en el edificio, para dar respuesta a diversas formas de utilización por parte de estudiantes y profesores. Se justifica la concentración de los espacios colectivos y de mayor tránsito en las plantas más próximas a la baja para facilitar el acceso rápido con el exterior, incluso el posible funcionamiento del museo, el auditorio, el comedor o la "sala caramelo", independientes del resto de la escuela. Los departamentos y la biblioteca tratarían de separar estos espacios con un horario de uso menos regulado, de las aulas y la zona de los talleres, que pasaron a ocupar los niveles superiores del edificio. Esta distribución era compatible con el modelo de enseñanza perseguido por Artigas que trataba de acabar con la 

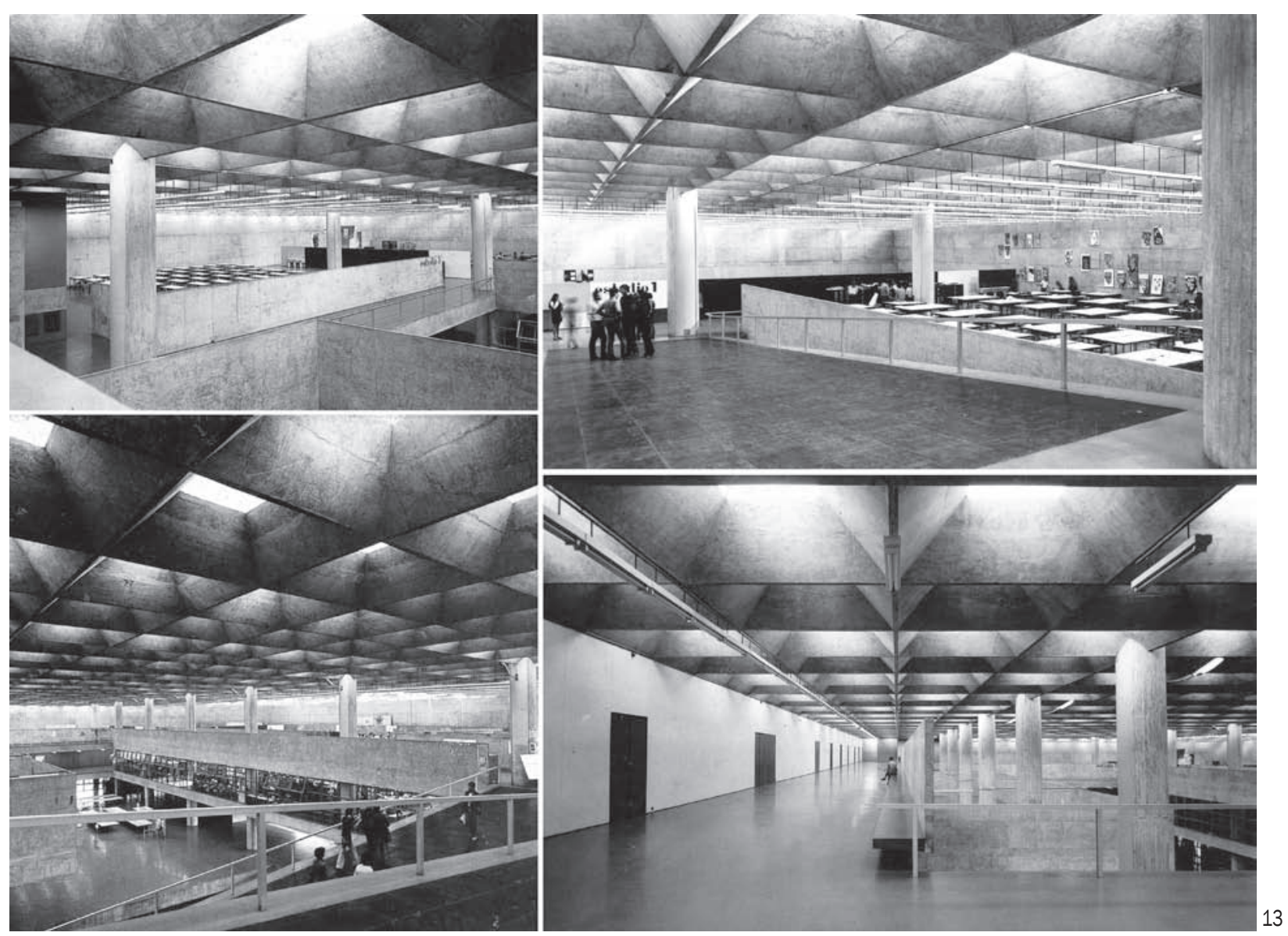

formación académica precedente. En la Reforma del año 1962, diseñó cuatro grandes bloques sobre los que se estructurarían la docencia: además de "Proyectos", incorporó "Urbanismo", "Comunicación Visual" y "Diseño Industrial". En el año 1968, Artigas reformó esta idea inicial encomendando a "Proyectos" la estructuración docente de los cuatro grupos que a su juicio abarcarían todos los contenidos de la formación del arquitecto: "Comunicación Visual", "Diseño Industrial", "Edificios" y "Paisaje"13. Quedaba claro que la forma de disponer el programa tenía la intención de facilitar el trabajo de estudiantes y profesores. La concentración en un ala de todos los departamentos y del taller interdepartamental iría encaminada al intercambio de información y puesta en común de las enseñanzas a impartir por los grandes bloques de los dos planes.
Artigas quería también convertir su modelo de enseñanza en un modelo social basado en la confianza, en los beneficios que reportaba el debate colectivo y en la continua interacción de las ideas. Por ello, la visibilidad dentro del edificio debía ser máxima y la presencia de una persona no debía pasar desapercibida para así quedar involucrada en las actividades individuales y colectivas que se estuviesen desarrollando en ese momento. En opinión de Artigas, en una universidad, todos los trabajos que realizaban estudiantes y profesores debían ser lícitos, ser conocidos por todos en beneficio de todos; las puertas debían entonces desaparecer para poder caminar sin encontrar límites en el horizonte. Edificio y modelo de enseñanza se integraban para cerrar un discurso teórico que tenía en los talleres, de espacios abiertos y continuos, los

10. En los "Vestiários de Sao Paulo Futebol Club" (1961), Artigas se aproxima más a esta ruptura que Le Corbusier realiza en el edificio de la Asociación de Hilanderos de Ahmedabad para identificar la entrada y situar las escaleras. 11. NORBERG-SCHULZ, Christian. et DIGERUD, John Georg: Op. cit., p. 10.

12. Influencias y relaciones de la arquitectura de Wright en la de Artigas pueden consultarse en IRIGOYEN, Adriana: Wright e Artigas. Duas viagens. Brasil: Ateliè Editorial, 2002. Algunas de las obras de Wright organizadas en torno a un atrio con luz cenital son el Larkin Company Administration Building (Buffalo, New York, 1903), la Unity Temple (Oak Park, Illinois, 1904), el S.C. Johnson and Son Co. Administration Building (Rancine, Wisconsin, 1936) o el Solomon R. Guggemheim Museum (New York, 1943-59).

13. En las reformas de los planes de estudio de los años 1962 y 1968 se fundamenta la creación de los tres departamentos que identifican hoy a la FAU: Proyectos, Historia de la Arquitectura y Tecnología de la Arquitectura. 
lugares de comprobación de esta forma de enseñanza, y en el proyecto, la única herramienta eficiente para un pensamiento creativo y para la integración de teorías y otras disciplinas técnicas. Situadas en la fachada sur y en el último nivel, el resto de aulas quedaban para una docencia más específica. Artigas había construido un modelo para una enseñanza de masas partiendo de sus irrenunciables principios ideológicos: frente a la universidad de élite, estaba convencido de que su sistema formaría arquitectos con actitudes menos conformista con lo preestablecido, más involucrados en la mejora de las condiciones de vida de las personas ${ }^{14}$.

La obra de Artigas legaba una última enseñanza, quizá más duradera que las derivadas de su plan de estudio. EI edificio de la F.A.U., aún siendo ejecutado con un material que debía ser manipulado en obra como era el hormigón armado, resultaba ser una arquitectura "precisa" porque en ella se pueden reconocerse las distintas apreciaciones que sobre este término observó Vittorio Gregotti ${ }^{15}$. Es una arquitectura precisa porque "construye sus propias reglas, las cuales establecen un orden propio específico de modificaciones de lo real y de la tradición de la disciplina"; porque el resultado obtenido está organizado siguiendo dichas reglas, legibles en sus espacios, en la estructura, en el programa funcional o en el modelo de enseñanza; y finalmente, porque Artigas consigue construir el edificio "con el máximo de economía de medios técnicos y expresivos en relación con la propia necesidad,... proporcional a su capacidad transformadora". El edificio del arquitecto brasileño se convertía en una excelente lección de arquitectura para sus estudiantes que ejemplificaba con sus acabados modestos, simples y económicos pero precisos, la obligación desde el proyecto de diseñar una arquitectura capaz de agotar todas las posibilidades prácticas y razonables, en el empleo de medios, mano de obra, materiales, color, etc., para poder alcanzar el máximo rendimiento posible.
No se olvidan los inconvenientes de una solución llevada al límite; los problemas de acondicionamiento térmico de los espacios abiertos y especialmente, los derivados del ruido que provocarían los estudiantes, en los debates y exposiciones de sus proyectos o simplemente, en su relajado transitar por el edificio ${ }^{16}$. Artigas confiaba en el respeto a las actividades individuales y colectivas, valorando por encima de todo el silencio necesario. No era sin embargo una situación que se correspondiese con la realidad social y sobre todo política; la "sala caramelo" se erigió en el espacio representativo de la lucha por las libertades perdidas en un momento donde la participación de todos los estudiantes resultaba imprescindible. Con el paso del tiempo, cesan las ideologías por las que tanto se lucharon, el contexto histórico se altera, las prioridades de la sociedad cambian, la tecnología queda obsoleta,... y al final, lo que permanece es la arquitectura. Pueden cambiar los modelos o los instrumentos para el aprendizaje de la arquitectura pero nunca una plaza en una ciudad necesitó una razón para ser utilizada, tan sólo la voluntad y los deseos de las personas que allí habitaban. La "sala caramelo" es uno de esos lugares que deberían ser habituales en el ámbito universitario, como lo fueron el ágora o el foro en las ciudades antiguas.

Observando las fotografías de la F.A.U., leyendo los textos de Artigas, redibujando sus planos, parecen que ahora tan sólo nos expresan espacios y silencios, los que también podríamos llegar a observar y escuchar en el propio edificio. Pero como indicaba Gregotti, esta contemplación sensorial lúcida, es necesaria primero para reconocer, y después, para resolver nuevos problemas, disponiendo otra vez en tensión todos los verdaderos condicionantes que hacen surgir a la arquitectura. La buena arquitectura siempre se ofrece de ejemplo y su enseñanza será tan imperecedera como nosotros queramos; sería deseable que dentro de unos años, despejadas las incertidumbres actuales, aún encontráramos espacios - de convivencia- que observar y silencios que escuchar.

14. Para una aproximación a las diferencias entre la universidad de élite y de masas consultar DE CARLO, Giancarlo: Planificazione e disegno delle Università. Roma: Edizione Universitarie Italiane, 1968.

15. GREGOTTI, Vittorio: Desde el interior de la arquitectura. Un ensayo de interpretación. Barcelona: Ediciones Península, 1993. p. 55.

16. El edificio ha presentado patologías en el hormigón, afectado por la acción combinada de los agentes atmosféricos. Las filtraciones de agua en la cubierta han obligado a colocar un techo de policarbonato sobre los lucernarios. MELENDEZ, Adilson: "Solução humilde, sobrecobertura quer evitar infiltrações na FAU/ USP". Projeto: revista mesal de arquitectura. 2009, n³ 348, p. 122. 


\section{Bibliografía}

ALFIERI, Bruno: “Joao Vilanova Artigas: ricerca brutalista”. Zodiac, 1960, nº 6, pp. 96-107.

ARTIGAS, Vilanova: “Vilanova Artigas”.Projeto. Sao Paulo: Projeto Editores Associados, 1984, nº 66, pp. 71-96.

ARTIGAS, Vilanova: Vilanova Artigas. Lisboa: Editorial Blau, Lda., 1997.

ARTIGAS, Vilanova:. Caminhos da arquitetura. Sao Paulo: Lech - Livraria Editora Ciencias Humanas Ltda, 1981.

FERREIRA MARTINS, Carlos: "Vilanova e la architettura moderna in Brasile". En Casabella, Milano: n 756, giugno 2007, pp. 32-39.

GREGOTTI, Vittorio: Desde el interior de la arquitectura. Un ensayo de interpretación. Barcelona: Ediciones Península, 1993.

IRIGOYEN, Adriana: Wright e Artigas. Duas viagens. Brasil: Ateliè Editorial, 2002

KAMITA, Joao Masao: Vilanova Artigas. Sao Paulo: Cosac \& Naify Ediçoes. Espaços da arte brasileira, 2000.

MILAN ACAYABA, Marlene: “Vilanova Artigas, amado mestre”. En Projeto. Sao Paulo: Projeto Editores Associados, 1985, n 76, pp. 50-54.

NORBERG-SCHULZ, Christian. et DIGERUD, John Georg: Louis I. Kahn, idea e imagen. Madrid: Xarait Ediciones, 1990.

PORTUGAL ALBURQUERQUE, Roberto (coordinador): Caderno dos riscos originais: projeto do edifício da FAUUSP na Cidade Universitária. João Batista Vilanova Artigas. Sao Paulo: FAU-USP, 1998.

RIBEIRO R, et alt (coordinador): Vilanova Artigas arquitecto. A cidade é uma casa. A casa é uma cidade. Sao Paulo: Centro de Arte Contemporânea. Câmara Municipal de Almada, 2001,

SEGAWA, Hugo: "Artigas o mestre desconocido". En Projeto. Sao Paulo: Projeto Editores Associados, 1985, n 72, pp. 42-44

SEGAWA, Hugo: "Duas entrevistas inédits de Vilanova Artigas". En Projeto. Sao Paulo: Projeto Editores Associados, 1988, n 109, pp. $92-102$.

VIERIA FILHO, Carlos Alberto: "Vilanova Artigas e a arquitetura paulista". En Projeto. Sao Paulo: Projeto Editores Associados, 1984, nº66, pp. 97101.

\section{Documentación gráfica}

Los dibujos de este artículo han sido realizados por Jaime Pérez Fiz, estudiante E.T.S. de Arquitecura de Sevilla (plan 98) y dirigidos por Amadeo Ramos Carranza.

Amadeo Ramos Carranza (Sevilla, 1963), Arquitecto (1989) y doctor en arquitectura (2006) por la Universidad de Sevilla. Profesor del Departamento de Expresión Gráfica Arquitectónica (1990-95); desde 1996, del Departamento de Proyectos Arquitectónicos, ETSA Sevilla. Pertenece al Grupo de Investigación HUM-632 “proyecto, progreso, arquitectura" (1997). Profesor invitado en la FAUT Lisboa (2006 y 2007). Director de las exposiciones y de los catálogos "Arquitectura del Racionalismo en Sevilla: Inicios y Continuidades" y "Sevilla 1995-2005. Arquitectura de una década" (2003 y 2006, en colaboración con I. Capilla y J. I. Sánchez-Cid). Coordinador del Seminario y del libro "Construyendo Londres. Dibujando Europa" (2006). Codirector del Seminario Internacional "Arquitectura y construcción: el paisaje como argumento" (2007). Codirector de la colección "Ensayos para un nuevo hábitat urbano" (2009): Artículos: "Langham House Close. Viviendas colectivas en Ham Common. James Stirling y James Gowan, 1995-58” (2006); "Estructuras activas“(Revista COAM, 2008); "Profesión vs Investigación (con algunas referencias a la enseñanza de proyectos)" (Revista ARTiTEXTOS, Lisboa 2008); "Utopías de arquitectura: paisajes para otra ciudad" (2009); "De la utilidad de la investigación al confort de la ciudad" (2009). Varios artículos en "La vivienda moderna. Registro DOCOMOMO ibérico. 1925-1965" (2009) 